\title{
Exploitation and Oppression in Erik Olin Wright's Social Theory, and a Marxian Complement
}

\author{
João Alexandre Peschanski ${ }^{1}$
}

\begin{abstract}
Exploitation and oppression remain key concepts in Erik Olin Wright's social theory, and this piece provides a general mapping of those concepts. These concepts are defined and their connection is cleared out. Marx's theory of industrial reserve army is discussed to make the point that non-exploited workers are potentially useful for understanding how apparently superfluous people for exploiters have an impact on exploitation dynamics. Marx's point contributes to Wright's overall conceptual enterprise.
\end{abstract}

Keywords: Marxism, Exploitation, Social Theory

In this piece I investigate the relationship between exploitation and oppression in Erik Olin Wright's work. Both concepts remain foundational to Wright's sociological enterprises. Such enterprises include a two-decade-long project to make sense of classes in contemporary societies and a decade-long project on envisioning alternatives to the prevailing system of social relationships. To investigate the relationship between exploitation and oppression touches upon the core of Wright's work.

The parts of this investigative piece are twofold. First, I summarize Wright's framework of oppression and exploitation. I show the relation between the concepts and discuss tensions in Wright's framework. Second, I discuss his claim that exploitation remains one specific type of economic oppression; he

\footnotetext{
${ }^{1}$ Sociology PhD candidate, UW-Madison. I thank Erik Olin Wright and the participants at the UW-Madison seminar "Class, State and Ideology: An Introduction to Social Science in the Marxist Tradition" (2009). I am also grateful for the helpful comments of the anonymous referees. Responsibility for all errors is mine.
} 
defines exploitation as 'exploitative economic oppression."2 Relying on Marx's Capital, I discuss the role of people who are not economically exploited in guaranteeing the social reproduction of exploitative relations. The summary of Wright' framework and the discussion on exploitation and economic oppression aim to clarify some of his contributions.

\section{Exploitative-Economic-Oppression Communal Identity}

Figure 1-Wright's Conceptual Frame of Oppression and Exploitation summarizes Wright's conceptual framework on the relationship between oppression and exploitation. The characteristics of that framework are threefold. Firstly, the argument is abstract rather than concrete. In that sense, abstract concepts are synthetic representations of phenomena, and concrete concepts remain a particular and historicized representation of phenomena, so that specific intervening determinations qualify - or even reverse - underlying expected tendencies of phenomena. For instance, one would have to distill elements of the American and the Swedish Capitalism - two distinct concrete phenomena - to get an abstraction called Capitalism. Such distinction relates to Marx's differentiation between levels of abstraction; to prove that claim would deflect me too much from the paper's goal. Secondly, the framework is relatively formal rather than substantial. I think of it as a computer file frame. When one clicks on a main file in a computer, a window with other files pop up. What differentiates the main file from the others is only the level of specificity. For instance, to get to exploitative economic oppression in Wright's frame, one must open the file Communal Identity Formation, then the file Oppression and finally Economic. I have not included most ramifications of Wright's frame in Figure 1; I have emphasized the conceptual path to exploitation. Thirdly, the building of the framework is logically sound rather than empirically driven. Even though Wright has engaged into quantitative and qualitative-method sociological enterprises, he situates his conceptual framework as solving theoretical puzzles in the Marxist tradition. To solve these puzzles, such as the class location of the

\footnotetext{
${ }^{2}$ My argument throughout this paper rests upon Wright $(1989,1994,1997)$.
} 
PESCHANSKI, João Alexandre. Exploitation and Oppression in Erik Olin Wright's Social Theory, and a Marxian Complement

middle class, ${ }^{3}$ he engages in discussions about incongruencies of competing explanations, and he emphasizes the reasoning behind his claims. The strong logical base of Wright's arguments strengthens the generalizability of his conceptual framework.

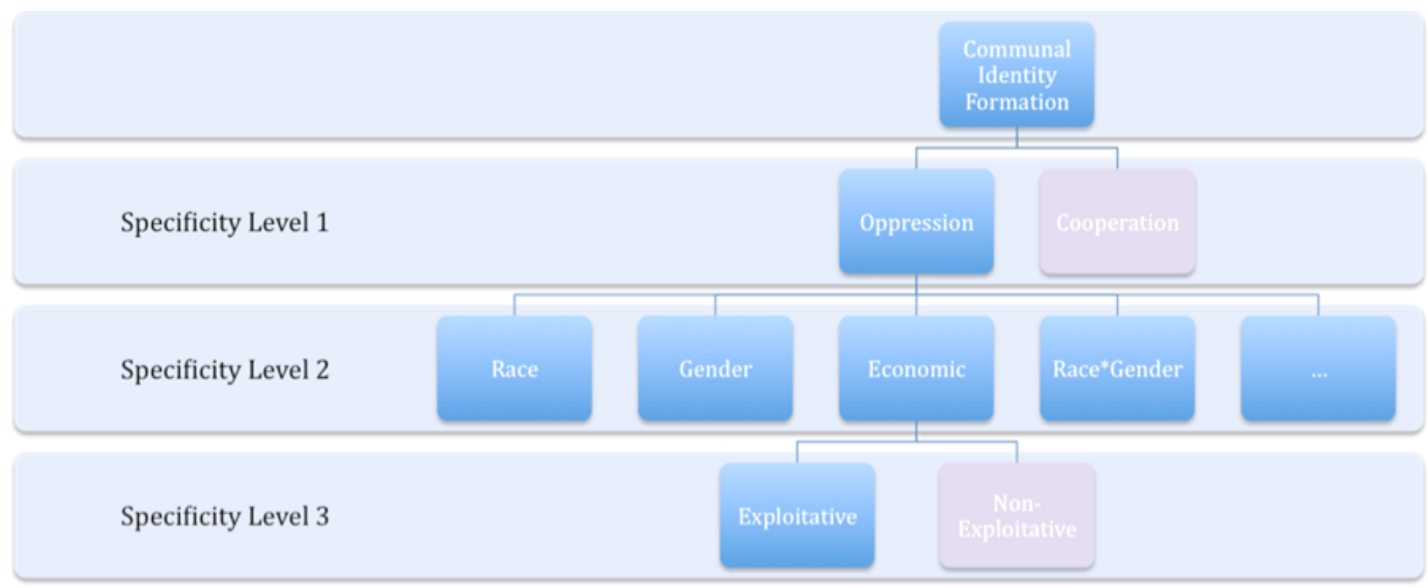

Figure 1-Wright's Conceptual Frame of Oppression and Exploitation

Communal identity formation is the more general concept in the Wrightian framework and refers to regular social interactions that build social categories and shared views on society. Such regular interactions drive people's attitudes and the pattern of interactions with other individuals. To define this concept Wright relies on Michael Albert and Robin Hahnel's work (1981). The overall idea of communal identity formation is not to look at general mechanisms that lead to the formation of social categories, but to assess in relational terms how individuals interact with each other and based on those interactions might have in abstract diverse interests. In Wright's work, the concept serves two analytical purposes. First, it sets up the unit of analysis. Individuals embedded in relations remain the basic actor. An example of communal identity formation is class formation: "[class formation] refers to the

\footnotetext{
${ }^{3}$ The study of class locations in class structures has been one of the main sociological contributions of Wright. At the same time breaking with the traditional Marxist view of proletarianization of the working class and building on the Marxian general framework, he considers that the middle class has, to some extent, characteristics of both the working and capitalist classes, thus being on a contradictory class location. For instance, managers sell their labor power just like workers, but they dominate workers in production just like capitalists. According to that perspective, class relations become multidimensional, in a crossing of exploitation and domination.
} 
formation of collectively organized social forces within class structures in pursuit of class interests. [...] Any form of collectively constituted social relations which facilitate solidaristic action in pursuit of class interests is an instance of class formation" (Wright, 1997 pp. 191-2). Second, communal identity formation has no substance as a concept, just referring to a broad formal description of social life, and thus becomes an analytical tool to treat equally different forms of social classification and to look for overlapping and interactions among them. Communal identity formation does not say anything about how and why people form communities.

Wright distinguishes two specific forms of communal identity formation: cooperative and oppressive. Cooperative communal identity, according to him, relies on trust, cooperation and sociability, and interactions remain with different degrees empowering and reciprocal (Wright, 2010). Domination and exclusion base oppressive communal identities. It is worth noticing that Wright refers in some occasion to exploitation as a form of cooperation, in the sense that exploiters depend on the "cooperation" of the exploited; here, he is invoking systematically coordinated interconnected practices, not some ideal of natural goodness or symmetrical reciprocity. Both forms of communal identity -cooperative and oppressive -- are self-reproducible in abstract, as long as social organizations and institutions upon which they rest do not collapse due to inner flaws. Thus, the political agenda that motivates struggles against oppression is not restoring a "natural order" of kindness but removing a human harm. The argument for creating conditions for human flourishing is not that it is "natural" for human beings to flourish, just that it is possible and desirable.

In Wright's framework, specificity refers to providing a theoretical understanding of a particular form of social interaction so that we know when specific empirical cases should be treated as similar or different, as falling under the same broad category or not. Three aspects of that definition are important to understand the Wrightian Social Theory. First, the difference of levels of specificity is a theoretical construction, contributing to concept-building. Second, one of the aims is to clarify similarities and differences between cases. In that sense, cooperation and oppression are similar (because they are both communal structures or relations) and different (because they do not rest upon the same kinds of interactions). This second aspect indicates that Wright aims 
PESCHANSKI, João Alexandre. Exploitation and Oppression in Erik Olin Wright's Social Theory, and a Marxian Complement

to make typologies. Third, the definition of specificity theory outlines a research agenda for investigating particular forms of interaction: 1) to locate within which broad categories a particular form of interaction is; 2 ) to find out what makes a particular form of interaction different from others in the same broad category of interactions; and 3) to organize empirical cases based on the conceptual framework.

Many dimensions of oppressive communal identities exist, according to Wright. In Figure 1, I mention "Race," "Gender," "Economic," "Race*Gender," and "...," and I now discuss each one of them. The same labels could exist as dimensions of cooperation communal identities. In a genuinely non-racist society, however, racial dimensions would almost certainly disappear; people might still note and observe phenotypic differences of people connected to kinship and ancestry, but these would not be consolidated into distinct bounded "racial" categories. The five dimensions aforementioned are similar to the extent that they share being specific categories of the same broader category; in that case, they are all oppressive forms of communal identity. Dimensions qualify and specify the broader category, so that gender and race are not nouns in the formal framework, rather adjectives. According to Wright, the specificities of race - which differentiate it from other social classifications - are at least twofold: hereditary biological base and visible physical attribute. Thus, racial oppression relates to harmful social classifications based on some biological elements. Some other specificities would come into play to define what gender oppression is. Race and gender oppression, however, might come to interact, that is, they are not simply additive, but have interactive consequences. Such interaction does not challenge the existence of race and gender as independent specific dimensions, rather generate a new specific form of oppression, a byproduct of the interconnection of race and gender oppression: "race* $g$ ender oppressive communal identity." The interconnection between race and gender oppressions is harder to imagine than between race and economic oppression or between gender and economic oppression. Wright investigates the latter indepth (1997 pp. 113-82). Considering that the possibilities of social classifications are endless and that the possibilities of interactive terms between those social classifications are also endless, the specific dimensions of oppressive communal identities are infinite. Is that a weakness of the model? 
The point here is to specify the actual mechanisms at work in the world. The only sense in which one may specify too many forms of oppression is that one incorrectly identifies something as a distinct form of mechanism when it is not. One might over-complexify a schema in the sense that one loses site of the really important and powerful forms of oppression that fragment solidarities and impose harms. Furthermore, the over-encompassing framework might be a form not to give priority of dimensions of oppression over others, and remains in tune with current studies on intersectionality.

Wright sets three conditions that define economic oppression: "(a) The material welfare of one group of people is causally related to the material deprivations of another. (b) The causal relation in (a) involves coercively enforced exclusion from access to productive resources. (c) This exclusion in (b) is morally indictable" (Wright, 1994 p. 39). ${ }^{4}$ In that sense, economic oppression remains a relational concept: people are economically oppressed through their social relations to others; material accumulation occurs at the expense of people's deprivation. Economic oppressors sustain that tense relation through what Wright calls "coercively enforced exclusion:" a set of mechanisms that legitimizes the unequal access to material resources and represses attempts of the oppressed to challenge their deprivation. The basic components of economic oppression, that differentiates that specific form of oppression form others, are conditions (a) and (b): the relation between material welfare of some groups to the deprivation of others, and the production and reproduction of that unequal relation through the coercively enforced exclusion from resources of various sorts.

In a more specific level, Wright distinguishes between non-exploitative and exploitative economic oppression - he calls the latter exploitation. According to him, "The crucial difference between exploitation and non-

\footnotetext{
${ }^{4}$ In later formulations (Wright, 1997 pp. 1-39), he drops the idea of morality as an explicit condition, so I do not explore in-depth the moral component of his theory. The moral element comes back to the Wrightian Sociology in Envisioning Real Utopias, where Wright states characteristics of a global principle for humanity, relying on social and political justice, and presents an agenda to reject oppression on moral grounds: "Emancipatory social science seeks to generate scientific knowledge relevant to the collective project of challenging various forms of human oppression. [...] The word emancipatory identifies a central moral purpose in the production of knowledge - the elimination of oppression and the creation of conditions for human flourishing." In the real-utopia agenda, Wright does not limit the moral rejection to economic oppression only, but to all forms of oppression. To that extent, condition (c) in the definition of economic oppression does not differentiate that form of oppression from others, but remains a constant element in oppression, independent of the specificities of forms of oppression.
} 
exploitative oppression is that in an exploitative relation, the exploiter needs the exploited since the exploiter depends upon the effort of the exploited" (Wright, 1994 p. 40). Wright defines three conditions for exploitative economic oppression: the inverse interdependent principle, the exclusion principle and the appropriation principle. The first two principles are the conditions (a) and (b) in the economic-oppression definition. The third principle is "[...] the causal mechanism which translates exclusion into differential welfare [involving] the appropriation of the fruits of labor of the exploited by those who control the relevant productive resources," so that "The welfare of the exploiter depends upon the effort of the exploited, not merely the deprivations of the exploited" (Wright, 1997 p. 10). This dependency shapes the interactions of exploiters and exploited, since the former might downplay their domination to stimulate the latter to work harder. Thus, all concrete forms of exploitation are always economic oppressions, whereas not all forms of economic oppressions are exploitative. According to Wright, exploiters do not depend on the effort of economically non-exploited oppressed to generate surplus product, so those become superfluous. As I show below, this last claim is at most only partially correct.

\section{The Necessity of the Superfluous}

Wright makes the case that the effort of economically non-exploited oppressed is not necessary for the realization of surplus. According to Wright, an example of that situation is the relationship between the European settlers and Native American populations in North America: the settlers acquired material benefits at the expense of the Native American populations, in general by imposing a violent control over territories and by excluding the Native American populations from access to resources. The settlers did not need the Native American populations in order to increase the level of their welfare. From Wright's perspective, "In the case of non-exploitative oppression, the oppressors would be happy if the oppressed simply disappeared. Life would have been much easier for the European settlers in North America if the continent had been uninhabited by people. Genocide is thus always a potential 
strategy for non-exploitative oppressors" (Wright, 1994 p. 40). In an exploitative relation, the oppressors' welfare depends directly on the effort of the oppressed population. Genocide of the exploited is not a plausible option for the exploiters. The relationship between a company owner and the company workers remains an illustration of that situation: the owner's welfare depends on the deprivation and the exclusion of the workers from material resources, and simultaneously depends on the workers' production to accumulate capital. According to Wright, "This dependency of the exploiter on the exploited gives the exploited a certain form of power, since human beings always retain at least some minimal control over their own expenditure of effort. [...] there is generally systematic pressure on exploiters to moderate their domination in one way or another to try to elicit some degree of consent from the exploited, at least in the sense of gaining some level of minimal cooperation from them" (Wright, 1997 p. 11).

One's position in a relation of exploitation -- whether one if the exploiter or the exploited -- shapes in the abstract one's material interests. Owners of the means of production have a rational incentive to maximize, or optimize when conditions for maximization are not reproducible, their profits. Workers, who sell their labor power, have an incentive to maximize, or optimize when conditions for maximization are not reproducible, their emancipation from the labor market, that is, socially necessary conditions of having a flourishing life with independence from the market. Material interests influence one's decisions: capitalists have a rational incentive to intensify workers' effort in production, since profits depend from it, whereas workers have a rational incentive to resist the appropriation of the product of their labor. Wright aims to depart from Marx, whose theory of exploitation based on the labor theory of value he rejects (Wright, 1994), yet the Marxian approach to non-exploited population contributes to understanding how exploitation and non-exploitative economic oppression go together.

According to Marx, capitalism -- an economic structure rooted on exploitation -- depends on the production and reproduction of non-exploited workers, that is, people who could be exploited but are not. As he says, "it is capitalist accumulation itself that constantly produces, and produces indeed in direct relation with its own energy and extent, a relatively redundant working population, i.e. a population which is superfluous to capital's average 
requirements for its own valorization, and is therefore a surplus population" (Marx, 1990 p. 782). Pauperism grows "in direct relation with" the advance of capitalism. The amount of the surplus population depends on the dynamics of capital, according to Marx; ${ }^{5}$ in special, investments in constant capital come generally with the exclusion of laborers from the production system. Marx's interpretation of the surplus population - which focuses on the inner logic of the capitalist mode of production - rejects the Malthusian approach, according to whom: "When wages are high, workers over-reproduce themselves. The consequent population increase produces a supply of labor larger than the demand and wages fall to their natural price. As this natural price only gives to the workers a minimum level of subsistence, the only way in which workers can improve their condition is by controlling their numbers thereby raising the price of labor. Poverty and unemployment are, therefore, only the result of the workers' natural propensity to reproduce beyond the available means of subsistence" (Gimenez, 1971). In the capitalist mode of production, workers do not escape their becoming superfluous, according to Marx.

In capitalism, the worker and people who are dependent from him/her selling his/her labor force are dependent on some capitalist or the state having use for this labor capacity. The worker and his/her dependents face constantly an uncertain future; they do not know whether or not they will have enough to meet their subsistence requirements. Marx calls the worker a "virtual pauper:" "He can live as a worker only in so far as he exchanges his labour capacity for that part of capital which forms the labour fund. This exchange is tied to conditions which are accidental for him, and indifferent to his organic presence. $\mathrm{He}$ is thus a virtual pauper. Since it is further the condition of production based on capital that he produces ever more surplus labour, it follows that ever more necessary labour is set free. Thus the chances of his pauperism increase"

\footnotetext{
${ }^{5}$ It is worth emphasizing that this if Marx is saying that the production of surplus population, overall a social demographic phenomenon, is only dependent on dynamics of accumulation then his statement does not seem to make sense. Demographic research that looks at the relationship between the decline in birth rates and the decline in death rates generally see the death rates declining more quickly than birth rates, and things like even minimal state provision of old age social security as tremendously affecting birth rates. The magnitude of the surplus population is a function of the combined magnitudes of (a) the job creation process (which is directly determined by accumulation dynamics), (b) the death rate, and (c) the birth rate. The determinants of (b) and (c) in contemporary demography do not seem to be Malthusian in any way: it has to do with things like literacy (especially female literacy), technological advances in public health, and the risk and old age insurance strategies of people. Unless (b) and (c) are also directly determined by capital accumulation without other dynamics or mediations, then one cannot derive the trajectory of the surplus population from accumulation (dynamics of capital) alone.
} 
(Marx, 1973 p. 604). Marx claims that capitalists use workers' fear of pauperism to their advantage.

Marx argues, therefore, that surplus populations are "necessary" for maintaining exploitation. The ways in which capitalists use the pool of necessary surplus workers - "the industrial reserve army" - are at least twofold: "the industrial reserve army, during the periods of stagnation and average prosperity, weighs down the active army of workers; during the period of overproduction and feverish activity, it puts a curb on their pretensions" (Marx, 1990 p. 792). A small reserve army jeopardizes the capitalists' ability to maintain their rate of exploitation; for instance, in colonies where settlers may buy land easily, wage laborers are rare, and capitalists need to raise salaries and reduce their rate of profit in other to maintain production (Choudhury, 2009 p. 17).

Based on what he observes in the 19th-century industrial capitalism, Marx distinguishes three kinds of industrial reserve army: the floating, the latent, and the stagnant. The former comprises workers who are displaced from employment to unemployment, and vice-versa, depending on fluctuations of the production system. Marx defines the latent reserve army as "part of the agricultural population [who] is constantly on the point of passing over into an urban or manufacturing proletariat" (Marx, 1990 p. 796). In the case of the United States, for instance, Mexican migrants are a "modern" form of latent reserve army, supplying excess labor force that American capitalists use to fill vacant job positions and to force down workers' salaries (Foley, 1986 p. 65). The last kind of industrial reserve army - the stagnant - gathers unskilled workers, who survive on the margins of the production system: from the perspective of the capitalists' interests, they remain "an inexhaustible reservoir of disposable labour-power" (Marx, 1990 p. 796). Marx adds to the three kinds of the industrial reserve army a fourth segment of the surplus population, that remains "unnecessary" to capitalists: the chronic paupers.

The chronic paupers - the "unnecessary" surplus population from the perspective of the capitalists - consist of three groups apart from the lumpemproletariat, according to Marx. First, people who are able to work; second, orphans and pauper children; third, "the demoralized, the ragged, and those unable to work, chiefly people who succumb to their incapacity of adaptation, an incapacity which results from the division of labor; people who 
PESCHANSKI, João Alexandre. Exploitation and Oppression in Erik Olin Wright's Social Theory, and a Marxian Complement

have lived beyond a worker's average life-span; and the victims of industry, whose number increases with the growth of dangerous machinery, of mines, chemical works, etc. the mutilated, the sickly, the widows, etc." (Marx, 1990 p. 797).

Marx connects his account of surplus population to his economic understanding of exploitation, based on the labor theory of value, but such connection is not necessary. The idea of a surplus population that is impactful on dynamics of exploitation -- by "weighing down" active workers and "curbing" workers' agendas -- is overall sociological: in the abstract, capitalists can threaten their employees by saying that if they do not work harder unemployed workers who are available in the labor market could potentially supplant them. Hence, capitalists might use any surplus population to their advantage. In Wrightian terms, the economically non-exploited oppressed matter to the dynamics of exploitation, to the extent that they can empower capitalists over workers in their search for their material interests.

\section{Conclusion}

I have summarized Wright's framework on oppression and exploitation. Such framework is mostly normative, and remains abstract, formal and logically driven. I have specially paid attention to the different levels of specificity in his work, given that according to him exploitation remains a specific type of economic oppression; he defines exploitation as exploitative economic oppression.

Conceptually, I have shown that there is a potential interdependence between non-exploitative and exploitative economic oppression, especially clear in capitalism. I relied on Marx's theory of surplus population to show such interdependence. My point does not pose a direct challenge to Wright's framework, and should be seen as a contribution to his well-polished conceptual enterprise. 


\section{Bibliography}

Albert, Michael and Robin Hahnel. 1981. Marxism and Socialist Theory. Boston: S. End.

Choudhury, Kushanava. 2009. "Superfluous People" (PhD dissertation). New Haven: Yale.

Foley, Duncan. 1986. Understanding Capital: Marx's Economic Theory. Cambridge: HUP.

Gimenez, Martha. 1971. The Population Issue: Marx vs. Malthus. Journal of the Institute for Development Research.

Marx, Karl. 1990. Capital Volume I. London: Penguin Classics.

Marx, Karl. 1973. Grundrisse. London: Penguin Classics.

Wright, Erik. 1989. Classes. London: Verso.

Wright, Erik. 1994. Interrogating Inequality. London: Verso.

Wright, Erik. 1997. Class Counts. London: Verso.

Wright, Erik. 2010. Envisioning Real Utopias. London: Verso.

Submetido em 2012-01-09

Aceito em 2012-03-23 